\title{
Evaluation of hematologic profile may be needed for patients treated with oxcarbazepine
}

\author{
Gu Hyun Jung, MD, Su Jeong You, MD, PhD \\ Department of Pediatrics, Inje University Sanggye Paik Hospital, Seoul, Korea
}

Purpose: The major side effects of treatment with oxcarbazepine (OXC) are skin rash and hyponatremia. Hematologic side effects are reported rarely. The aim of this study was to investigate the rate and types of the hematologic side effects of OXC.

Methods: The medical records of 184 patients diagnosed with epilepsy or movement disorder and on OXC monotherapy, at the Department of Pediatrics of Inje University Sanggye Paik Hospital from July 2001 to July 2018, were retrospectively reviewed.

Results: Of the 184 patients, 10 (5.4\%) developed leukopenia in addition to pancytopenia and 2 (1.0\%) developed pancytopenia. Leukopenia developed in 11 days to 14 years after OXC administration and was more frequent in males than in females (male vs. female, 9 vs. 1; Fisher exact test, $P<0.05$ ). Of the eight patients with leukopenia alone, 7 continued OXC treatment; 6 improved without intervention; 1 was lost to follow-up; and 1 received a reduced OXC dose, who improved after intervention. Pancytopenia developed within 2 months of initiation of OXC treatment. Both patients initially continued OXC. One improved within 1 month and continued treatment with OXC, but the other showed progression of the side effect, leading to the discontinuation of OXC and subsequent improvement within 1 month. There were no significant differences in the ages of the patients, OXC dose, and duration of OXC treatment between patients with and without these side effects of OXC ( $P>0.05, t$-test).

Conclusion: OXC-induced leukopenia is not rare and may result in pancytopenia. Patients being treated with OXC should be regularly monitored for abnormal complete blood count profiles.

Key words: Oxcarbazepine, Complete blood count, Leukopenia, Pancytopenia

\section{Key message}

Question: Will oxcarbazepine cause hematologic side effects to the patients?

Finding: We found that oxcarbazepine can lead to leukopenia and pancytopenia. Oxcarbazepineinduced leukopenia is not rare (5.4\%) and can lead to pancytopenia (1.0\%). Both of them were occurred by chance without any symptom.

Meaning: Oxcarbazepine can induce leukopenia and pancytopenia, so evaluation of hematologic profile may be needed during oxcarbazepine therapy.

\section{Introduction}

Patients with pediatric epilepsy and movement disorders require long-term treatment with anticonvulsants. Drug selection is important in minimizing side effects. Oxcarbazepine (OXC), a keto derivative of carbamazepine (CBZ), is widely used as an alternative to CBZ for the treatment of children with partial, secondary generalized epilepsy and movement disorders. ${ }^{1)}$ Compared with CBZ, OXC has similar efficacy in reducing seizures but fewer side effects. ${ }^{2,3)}$ The most common side effects of OXC are skin rash, headache, dizziness, nausea,

Copyright (C) 2019 by The Korean Pediatric Society

This is an open-access article distributed under the terms of the Creative Commons Attribution NonCommercial License (http://creativecommons.org/ licenses/by-nc/4.0/) which permits unrestricted noncommercial use, distribution, and reproduction in any medium, provided the original work is properly cited. 
sedation and hyponatremia. ${ }^{4)}$ However, in contrast to CBZ, which has been associated with blood dyscrasias, ${ }^{5}$ OXC is relatively safe hematologically. ${ }^{6,7)}$ Although a few case reports have described leukopenia associated with OXC, all of these patients were receiving other agents in addition to OXC, such as levetiracetam and clonazepam ${ }^{8)}$ or valproic acid. ${ }^{9)}$ Another case report described pancytopenia associated with OXC in an adult, but this patient was taking sertraline, fosinopril, clonazepam and an oral contraceptive, in addition to OXC. ${ }^{10)}$ Of 42 children being treated with OXC monotherapy, 1 (2.3\%) developed leukopenia, leaded to the withdrawal of OXC, ${ }^{11)}$ however, to our knowledge, there have been no reports of OXC-associated pancytopenia and no studies on hematologic dysfunction in patients being treated with this agent. This retrospective, single center study assessed the rates of OXC-associated leukopenia and pancytopenia in pediatric patients.

\section{Materials and methods}

\section{Patients}

Patients aged $<18$ years who were diagnosed with epilepsy or a movement disorder and treated with OXC from July 2001 to July 2018 at Inje University Sanggye Paik Hospital were evaluated retrospectively. Patients were excluded if they also had other conditions that could lead to abnormalities in hematopoietic function, such as infectious diseases, trauma, and surgery. Of the 420 patients treated with OXC during this time period, 236 were excluded, 215 patients because they received polytherapy and 21 because their complete blood counts (CBC) were not determined. Finally, 184 patients were included. Data collected from all patients included age at OXC administration, sex, diagnosis, duration of OXC treatment, maintenance OXC dose, hemoglobin concentration, white blood cell (WBC) count, platelet count, and absolute neutrophil count (ANC). The onset and improvement of leukopenia were determined.

Patients were divided into 2 groups: those with and those without OXC-associated leukopenia, which was defined as a WBC count $<4.0 \times 0^{3} / \mu \mathrm{L}$. Among the patients with leukopenia, those with pancytopenia, defined as anemia, thrombocytopenia, as well as leukopenia, were described in detail.

The study protocol was approved by the Institutional Review Board of Inje University Sanggye Paik Hospital (2018-10-016).

\section{Statistical analysis}

Continuous variables, including age, duration of treatment, maintenance dose of OXC, and CBC profile, were expressed as mean \pm standard deviation and compared using $t$ tests. Categorical variables were compared using chi-square test. All statistical analyses were performed using IBM SPSS Statistics ver. 25.0 (IBM Co., Armonk, NY, USA), with statistical significance defined as a $P$ value $<0.05$.

\section{Results}

During the study period, 184 children, 104 boys and 80 girls, were treated with OXC. Of these, 174 (94.8\%), 95 boys and 79 girls, did not develop leukopenia. Their mean age at OXC administration was $8.02 \pm 3.41$ years, their mean duration of OXC treatment was $40.03 \pm$ 37.80 months, and their mean maintenance dose of OXC was $15.27 \pm 7.40 \mathrm{mg} / \mathrm{kg} /$ day. Leukopenia was observed in 10 children (5.2\%), 9 boys and 1 girl. The mean age at OXC administration was $8.00 \pm 3.36$ years, their mean duration of OXC treatment was $71.80 \pm 57.84$ months, and their mean maintenance dose of OXC was $15.2 \pm 7.08 \mathrm{mg} / \mathrm{kg} /$ day. The percentage of boys was significantly higher in the leukopenia group $(P<0.05$, Fisher exact test), whereas age at OXC administration, duration of OXC treatment, and dose of OXC did not differ significantly in the two groups (Table 1).

Leukopenia was first observed 11 days to 14 years after OXC administration (Fig. 1). Eight patients who had leukopenia alone showed

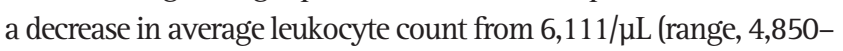

Table 1. The baseline clinical characteristics of patients treated with oxcarbazepine

\begin{tabular}{lccc}
\hline Characteristic & $\begin{array}{c}\text { Without } \\
\text { adverse } \\
\text { effects } \\
(\mathrm{n}=174)\end{array}$ & $\begin{array}{c}\text { With } \\
\text { leukopenia or } \\
\text { pancytopenia } \\
(\mathrm{n}=10)\end{array}$ & $P$ value \\
\hline Age $(\mathrm{yr})$ & $8.02 \pm 3.41$ & $8.00 \pm 3.36$ & $>0.05^{\mathrm{a})}$ \\
Sex & $95(54.6)$ & $9(90)$ & $\mathbf{0 . 0 2 8 ^ { \mathrm { b } }}$ \\
$\quad$ Male & $79(45.4)$ & $1(10)$ & \\
$\quad$ Female & $40.03 \pm 37.80$ & $71.80 \pm 57.84$ & $>0.05^{\mathrm{a})}$ \\
Duration of oxcarbazepine $(\mathrm{mo})$ & & & \\
Diagnosis & $168(96.5)$ & $9(90)$ & $>0.05^{\mathrm{c})}$ \\
$\quad$ Epilepsy & $6(3.5)$ & $1(10)$ & \\
$\quad$ Movement disorder & $15.27 \pm 7.40$ & $15.2 \pm 7.08$ & $>0.05^{\mathrm{a})}$ \\
\hline Dose of oxcarbazepine $(\mathrm{mg} / \mathrm{kg})$ & &
\end{tabular}

Values are presented as mean \pm standard deviation or number (\%).

Boldface indicates a statistically significant difference with $P<0.05$.

${ }^{\text {a) }} t$-test. ${ }^{\text {b) }}$ Fisher exact test. ${ }^{\text {C) }}$ Chi-square test.

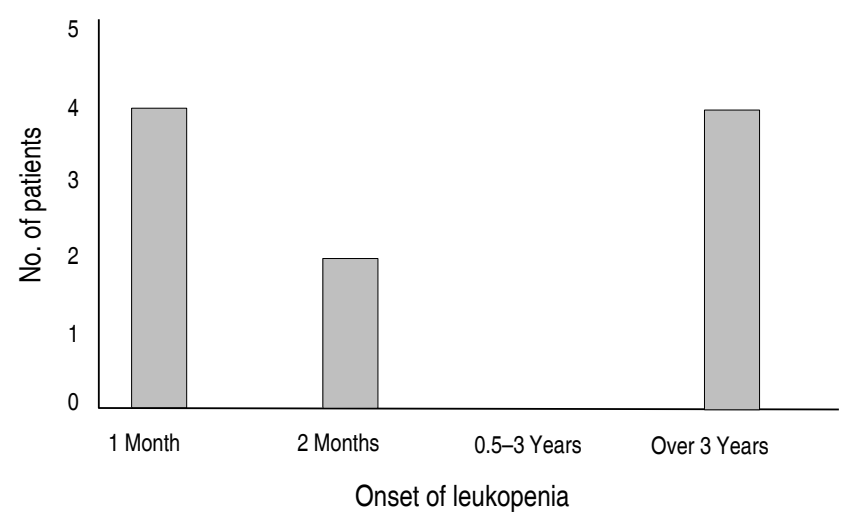

Fig. 1. Onset of leukopenia after oxcarbazepine administration. 
$7,700 / \mu \mathrm{L}$ ) to $3,710 / \mu \mathrm{L}$ (range, 3,110-3,950/ $\mathrm{LL}$ ) and in ANC from $3,552.5 / \mu \mathrm{L}$ (range, $2,490-4,930 / \mu \mathrm{L}$ ) to $1,602.5 / \mu \mathrm{L}$ (range, $850-$ 2,340/ $\mathrm{LL}$ ). After developing leukopenia, seven patients continued taking OXC, with six improving without further intervention, and 1 patient lost to follow-up. In 1 patient, who experienced reductions in leukocyte count to $3,110 / \mu \mathrm{L}$ and in ANC to $850 / \mu \mathrm{L}$, OXC dose was reduced from $8.8 \mathrm{mg} / \mathrm{kg}$ to $6.6 \mathrm{mg} / \mathrm{kg}$, increasing the leukocyte count to $5,990 / \mu \mathrm{L}$ and ANC to $3,380 / \mu \mathrm{L}$. This patient was continued on the reduced OXC dose.

Of the 184 patients, 2 patients (1.0\%) developed pancytopenia (Table 2). One patient, a boy aged 3 years 6 months diagnosed with focal epilepsy, was started on $5 \mathrm{mg} / \mathrm{kg} /$ day OXC monotherapy during the first week, with the dose increased to $11 \mathrm{mg} / \mathrm{kg} /$ day during the second week. After 28 days, his CBC profile was hemoglobin concentration $11.6 \mathrm{~g} / \mathrm{dL}$, leukocyte count $2,690 / \mu \mathrm{L}$, platelet count $129,000 / \mu \mathrm{L}$, and ANC 500/ $\mathrm{LL}$. He continued to take OXC, normalizing after another 28 days, as shown by hemoglobin con-

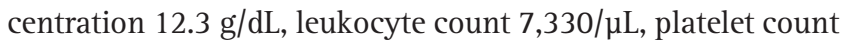
$251,000 / \mu \mathrm{L}$, and ANC 3,230/ $\mu \mathrm{L}$. He was maintained on OXC for 2 years with no recurrence of pancytopenia. The second patient with pancytopenia was a girl aged 9 years 5 months diagnosed with benign childhood epilepsy with centrotemporal spikes. Before OXC administration, her CBC profile was hemoglobin concentration 13.8 $\mathrm{g} / \mathrm{dL}$, leukocyte count $7,190 / \mu \mathrm{L}$, platelet count $186,000 / \mu \mathrm{L}$, and ANC $2,910 / \mu \mathrm{L}$. She developed leukopenia after 26 days of OXC treatment,

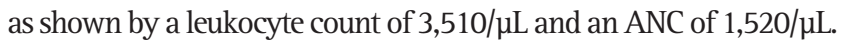
She continued taking OXC without intervention. A follow-up CBC after 53 days of treatment with $20 \mathrm{mg} / \mathrm{kg} /$ day OXC resulted in the development of pancytopenia, with a hemoglobin concentration of $10.0 \mathrm{~g} / \mathrm{dL}$, a leukocyte count of 2,620/ $\mathrm{LL}$, a platelet count of 102,000/ $\mu \mathrm{L}$, and an ANC of $1,310 / \mu \mathrm{L}$. OXC was discontinued, resulting in CBC normalization, as shown by hemoglobin concentration $14.1 \mathrm{~g} /$ $\mathrm{dL}$, leukocyte count 4,340/ $\mu \mathrm{L}$, platelet count 188,000/L, and ANC $2,290 / \mu \mathrm{L}$. Subsequently, she was started on levetiracetam. Neither of these patients developed symptoms during periods of pancytopenia.

\section{Discussion}

OXC, the 10-keto analogue of CBZ, is metabolized to 10,11-dihydro-10-hydro-10-hydroxy carbamazepine (mono-hydroxy derivative, MHD), which has antiepileptic effects. ${ }^{12)} \mathrm{MHD}$ binds to sodium channels, inhibiting sodium uptake and subsequent high-frequency repetitive firing. ${ }^{13)}$ Hyponatremia is the most common side effect in patients treated with OXC, with other side effects including skin rash, headache, dizziness, and nausea. ${ }^{4)}$

The hematologic side effects of antiepileptic drugs (AEDs), including leukopenia, thrombocytopenia, anemia, and aplastic anemia can lead to serious, life-threatening events. Several hypotheses have been proposed to explain the mechanisms by which a drug causes hematologic side effects, including bone marrow suppression, destruction of immune system related cells, and direct marrow toxicity. ${ }^{14,15)}$ Neutropenia or agranulocytosis is more common than the other drug-associated blood dyscrasias. ${ }^{16)}$ Mild leukopenia is relatively

Table 2. Summary of the patients with oxcarbazepine-induced pancytopenia

\begin{tabular}{lcc}
\hline Variable & Patient 1 & Patient 2 \\
\hline Age & 3 yr 6 mo & 9 yr 5 mo \\
Sex & Male & Female \\
Diagnosis & Focal epilepsy & Benign childhood epilepsy with centrotemporal spikes \\
Timing of leukopenia & 28 Days & 26 Days \\
Timing of pancytopenia & 28 Days & 53 Days \\
Dose of oxcarbazepine & 11 mg/kg/day & 20 mg/kg/day \\
CBC finding & (Baseline/onset/improving) & (Baseline/onset/progressing/improving) \\
Hemoglobin (g/dL) & $-/ 11.6 / 12.3$ & $13.8 / 13.7 / 10.0 / 14.1$ \\
WBC $(\mu \mathrm{L})$ & $-/ 2,690 / 7,330$ & $7,190 / 3,510 / 2,620 / 4,340$ \\
Platelet $(\mu \mathrm{L})$ & $-/ 129,000 / 251,000$ & $186,000 / 171,000 / 102,000 / 188,000$ \\
Absolute neutrophil count $(\mu \mathrm{L})$ & $-/ 500 / 3,230$ & $2,910 / 1,520 / 1,310 / 2,290$ \\
Peripheral blood smear & Not done & Mild neutropenia \& thrombocytopenia \\
Symptoms of pancytopenia & None & None \\
Other adverse effects & None & None \\
Other abnormal lab finding & None & None \\
Management & Observation & Observation after leukopenia \\
Improving date after pancytopenia & None & Stop oxcarbazepine after pancytopenia \\
Intervention & None & 26 Days
\end{tabular}

CBC, complete blood count; WBC, white blood cells. 
common, ${ }^{17)}$ whereas aplastic anemia and pancytopenia are rare. ${ }^{18)}$ Other AEDs are better known for their hematologic side effects. For example, long term phenytoin can cause mild leukopenia; valproic acid can cause thrombocytopenia and inhibit platelet aggregation; ${ }^{17)}$ and felbamate can cause aplastic anemia, limiting its use. ${ }^{19,20)}$

Although OXC has been reported to be relatively safe hematologically, this study showed that OXC can have an effect on the hematopoietic system. Its mechanism of action is unknown, but it is likely to be related with bone-marrow toxicity similar to that of $\mathrm{CBZ}$ because of their structural similarity. ${ }^{5}$ CBZ can induce leukopenia and aplastic anemia, ${ }^{21)}$ with blood dyscrasias induced by toxic metabolites, ${ }^{5)}$ suggesting similar mechanisms for the hematologic side effects of OXC.

This study reported the incidence, characteristics and outcomes of OXC-induced leukopenia and pancytopenia. Leukopenia in these patients was likely due to OXC because we excluded patients with other inducers of leukopenia such as other drugs, infection, trauma, and surgery. The incidence of leukopenia was not rare (5.2\%), although our finding, that most of these patients were asymptomatic, suggested that the incidence of leukopenia may be higher. Two patients (1.0\%) showed progression to pancytopenia, further indicating that OXC can affect the hematopoietic system and may cause serious side effects.

Except for male overpredominance in the leukopenia group, patient characteristics did not differ significantly in the groups with and without leukopenia. Six patients (60\%) developed hematologic side effects within 2 months (range, 11-53 days) after starting OXC, whereas the other $4(40 \%)$ took OXC for more than 3 years (range, 3-14 years). However, there was no significant difference between early and late onset OXC induced leukopenia, suggesting that it occurred by chance during maintenance treatment. Because side effects can occur at any time during treatment, $\mathrm{CBC}$ should be monitored continuously during treatment with OXC.

Most patients recovered spontaneously from leukopenia despite continuing the medication. However, a few patients developed serious side effects of pancytopenia, necessitating drug withdrawal or dose reduction. One patient maintained on OXC showed progression to pancytopenia, which improved after discontinuation of OXC. Continuation of OXC may worsen a patient's condition, making early detection important.

This study had several limitations, including its retrospective, single center design. Moreover, $\mathrm{CBC}$ was not routinely performed long-term in all patients. This may result in an inaccurate assessment of incidence, which may have been underestimated. In addition, it was difficult to compare patient characteristics due to large differences in the number of patients with and without side effects. Nevertheless, this study is the first to investigate the hematologic side effects of OXC. Further long-term prospective studies are needed.

In conclusion, OXC-induced leukopenia is not rare and may lead to pancytopenia. CBC should be regularly monitored during treatment with OXC, regardless of whether or not patients have abnormal CBC profiles.

\section{Conflict of interest}

No potential conflict of interest relevant to this article was reported.

\section{References}

1. Kalis MM, Huff NA. Oxcarbazepine, an antiepileptic agent. Clin Ther 2001;23:680-700.

2. Dam M, Ekberg R, Løyning Y, Waltimo 0, Jakobsen K. A double-blind study comparing oxcarbazepine and carbamazepine in patients with newly diagnosed, previously untreated epilepsy. Epilepsy Res 1989;3: 70-6.

3. Dam M. Practical aspects of oxcarbazepine treatment. Epilepsia 1994; 35 Suppl 3:S23-5.

4. Dichter MA, Brodie MJ. New antiepileptic drugs. N Engl J Med 1996;3 34:1583-90.

5. Knowles SR, Shapiro LE, Shear NH. Anticonvulsant hypersensitivity syndrome: incidence, prevention and management. Drug Saf 1999; 21:489-501.

6. Hitiris N, Brodie MJ. Modern antiepileptic drugs: guidelines and beyond. Curr Opin Neurol 2006;19:175-80.

7. Horga de la Parte JF, Horga A. Oxcarbazepine in the treatment of epilepsy. A review and update. Rev Neurol 2006;42:95-113.

8. Milia A, Pilia G, Mascia MG, Moller J, Cocco E, Marrosu MG. Oxcarbazepine-induced leukopenia. J Neuropsychiatry Clin Neurosci 2008; 20:502-3.

9. Son YR, Son YR, Kim YS, Kim YS, Chu K, Chu K, et al. Oxcarbazepine induced leukopenia. J Korean Epilepsy Soc 2013;17:22-3.

10. Calamaras MR, Stowe ZN, Newport DJ. Pancytopenia associated with the introduction of oxcarbazepine. J Clin Psychopharmacol 2007;27: 217-8.

11. Serdaroglu G, Kurul S, Tutuncuoglu S, Dirik E, Sarioglu B. Oxcarbazepine in the treatment of childhood epilepsy. Pediatr Neurol 2003;28: $37-41$.

12. Lloyd P, Flesch G, Dieterle W. Clinical pharmacology and pharmacokinetics of oxcarbazepine. Epilepsia 1994;35 Suppl 3:S10-3.

13. Benes J, Parada A, Figueiredo AA, Alves PC, Freitas AP, Learmonth DA, et al. Anticonvulsant and sodium channel-blocking properties of novel 10,11-dihydro-5H-dibenz[b,f]azepine-5-carboxamide derivatives. J Med Chem 1999;42:2582-7.

14. Balon R, Berchou R. Hematologic side effects of psychotropic drugs. Psychosomatics 1986;27:119-20,125-7.

15. Moss RA. Drug-induced immune thrombocytopenia. Am J Hematol 1980;9:439-46.

16. Flanagan RJ, Dunk L. Haematological toxicity of drugs used in psychiatry. Hum Psychopharmacol 2008;23 Suppl 1:27-41.

17. Mattson RH, Cramer JA, Collins JF, Smith DB, Delgado-Escueta AV, Browne TR, et al. Comparison of carbamazepine, phenobarbital, phenytoin, and primidone in partial and secondarily generalized tonicclonic seizures. N Engl J Med 1985;313:145-51.

18. Pisciotta AV. Drug-induced leukopenia and aplastic anemia. Clin Pharmacol Ther 1971;12:13-43.

19. Kaufman DW, Kelly JP, Anderson T, Harmon DC, Shapiro S. Evaluation of case reports of aplastic anemia among patients treated with felba- 
mate. Epilepsia 1997;38:1265-9.

20. Pennell PB, Ogaily MS, Macdonald RL. Aplastic anemia in a patient receiving felbamate for complex partial seizures. Neurology 1995;45 (3 Pt 1):456-60.
21. Franceschi M, Ciboddo G, Truci G, Borri A, Canal N. Fatal aplastic anemia in a patient treated with carbamazepine. Epilepsia 1988;29: 582-3. 